\title{
A GEODIVERSIDADE DOS MONÓLITOS DE QUIXADÁ/CE: UMA ABORDAGEM GEOTURÍSTICA DO PATRIMÔNIO LOCAL
}

\author{
Hermógenes Henrique Oliveira Nascimento ${ }^{(a)}$ \\ (a) Secretaria do Meio Ambiente do Ceará, henrique.sampa @ gmail.com
}

Eixo: GEODIVERSIDADE, GEOARQUEOLOGIA E PATRIMÔNIO NATURAL

\begin{abstract}
Resumo
O presente trabalho tem o objetivo de analisar a importância da geodiversidade local relacionando a identidade, memória e conservação em prol do desenvolvimento do geoturismo utilizando elementos do patrimônio natural e cultural do Monumento Natural Os Monólitos de Quixadá. Para isso, desenvolveram-se processos de investigação calcados principalmente em uma abordagem qualitativa com metodologia baseada na análise de conteúdo. Utilizou-se de pesquisas bibliográficas, em fontes documentais e empíricas. Essas consistiram em uma pesquisa de campo indagada a três grupos determinados pelo pesquisador que foram: da comunidade local inseridas na referida Unidade de Conservação (UC) (35 entrevistas), dos governos locais (5) e da iniciativa privada (10) envolvidos com o turismo e o meio ambiente. Por fim, entende-se que para ocorrer o desenvolvimento sustentável do turismo com enfoque na natureza é imprescindível que a relação entre memória, identidade e conservação se concretize na sociedade local.
\end{abstract}

Palavras chave: Geodiversidade, Geoturismo, Patrimônio, Unidades de Conservação

\section{Introdução}

\subsection{Geodiversidade, cultura e turismo em Unidades de Conservação: a problemática em questão}

$\mathrm{Na}$ academia é destacado o caráter multidisciplinar da atividade turística, comprovando-se também na prática, pois ela é vista pela diversidade dos setores envolvidos, seja da esfera governamental, seja da privada. Talvez seja por isso que no âmbito dos conceitos e definições de turismo exista uma enorme complexidade, o que tem justificado a dificuldade de se ter um conceito que atenda aos seus diversos aspectos.

Para iniciar as discussões neste trabalho cabe-se enunciar a concepção de turismo de Beni (2001), em que agrega a essa definições dimensões econômica, técnica e holística. Da mesma forma, no cotidiano, o turismo vem ocupando diversas categorias, seja de atividade econômica, social, cultural, meio de proteção e/ou degradação ambiental, dentre outras.

Para compreender melhor essas mudanças Canclini (1994) conceitua que, o patrimônio inclui a herança cultural de cada povo, os bens culturais produzidos pelos segmentos sociais em cada tempo histórico e também os bens culturais visíveis e invisíveis, tais como idioma, conhecimento, documentação, artesanato, 
entre outros.

Desde o final dos anos de 1950, o turismo tem se tornado uma importante variável na economia mundial. Ao longo das três últimas décadas o turismo tem sido reconhecido por vários países como uma valiosa estratégia de desenvolvimento socioeconômico. Neste cenário, o turismo tem despontado como um instrumento importante de dinamização do setor de serviços, uma vez que, segundo a Organização Mundial do Turismo (OMT), a atividade obtém receitas mundiais anuais de mais de US\$ 400 bilhões. A OMT prever que em 2020, o turismo mundial deverá alcançar receitas de aproximadamente dois trilhões de dólares.

Nesse sentido, Gray (2004), primeiro autor a expressar o termo, se refere à geodiversidade como a distribuição natural da geologia, incluindo rochas, minerais, fósseis, características dos solos, as formas do terreno e seus processos (geomorfologia), além das suas relações.

O conceito de geodiversidade nasce, sobretudo, no inicio da década de 1990, em contraponto ao conceito de biodiversidade, que a princípio levaria em consideração apenas a diversidade biológica e não a variação dos elementos abióticos (SERRANO CAÑADAS e RUYZ FLAÑO, 2007).

Já, Muggler (2007) considera que é preciso ampliar e disseminar a compreensão da geodiversidade, destacando sua importância não apenas econômica, rompendo com a atual postura de desvalorização desse recurso por parte da sociedade, promovendo uma nova percepção pública dos solos.

Esse conjunto, em muitas situações, apresenta aspectos cênicos interessantes ou didático-científicos e que precisam ser mais bem aproveitados e o seu uso turístico tem se demonstrado como uma alternativa. No mundo, estima-se que $10 \%$ seja a cota mínima de proteção de recursos pelas várias nações, sejam estas unidades agrupadas como unidades de proteção integral, cujo objetivo básico é preservar a natureza, sejam unidades de uso sustentável, onde se procura compatibilizar a conservação da natureza com as necessidades socioambientais das populações envolvidas. O Estado do Ceará já alcança 6,5\%, porção considerável do espaço cearense protegido e que dará respostas futuras aos esforços gerados para garanti-los.

No pano de fundo, têm-se as Unidades de Conservação (UC) que são áreas naturais sob regime especial de administração, criadas legalmente pelo Poder Público, com localização e limites definidos. Em geral, possuem características ecológicas ou paisagísticas especialmente importantes, com elevada riqueza de espécies de flora e fauna, presença de espécies raras, endêmicas ou ameaçadas de extinção, amostras representativas de diferentes ecossistemas, significativa beleza cênica, ou recursos naturais indispensáveis para o bem-estar das comunidades humanas. Atualmente, no Estado do Ceará, temos 24 (vinte e quatro) Unidades de Conservação e um Corredor Ecológico que são administrados pela Secretaria do Meio Ambiente - SEMA.

Em função da fragilidade dos diversos sistemas ambientais do Estado e os atributos bióticos e abióticos,

estéticos ou culturais especialmente importantes para a qualidade de vida e bem estar das populações 


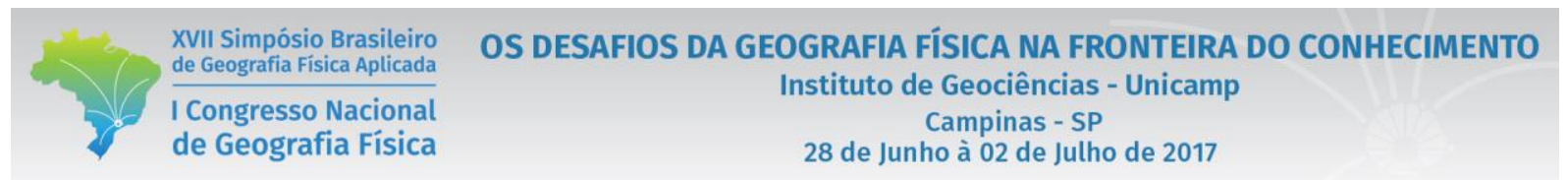

humanas, o Governo do Estado vem adotando medidas que têm por finalidade a proteção e preservação da biodiversidade, geodiversidade e o disciplinamento do processo de ocupação, visando assegurar a sustentabilidade do uso dos recursos naturais.

O Monumento Natural Os Monólitos de Quixadá é uma Unidade de Conservação de Proteção Integral, com uma beleza cênica de grande valor paisagístico, ecológico e turístico que encerram os campos de inselbergs existentes na região. Os inselbergs da região, popularmente conhecidos como Curral de Pedras, apresentamse em forma de serrotes (monólitos), construindo uma paisagem formada por relevos residuais distribuídos sobre áreas pediplanadas, como mostrado na figura abaixo.

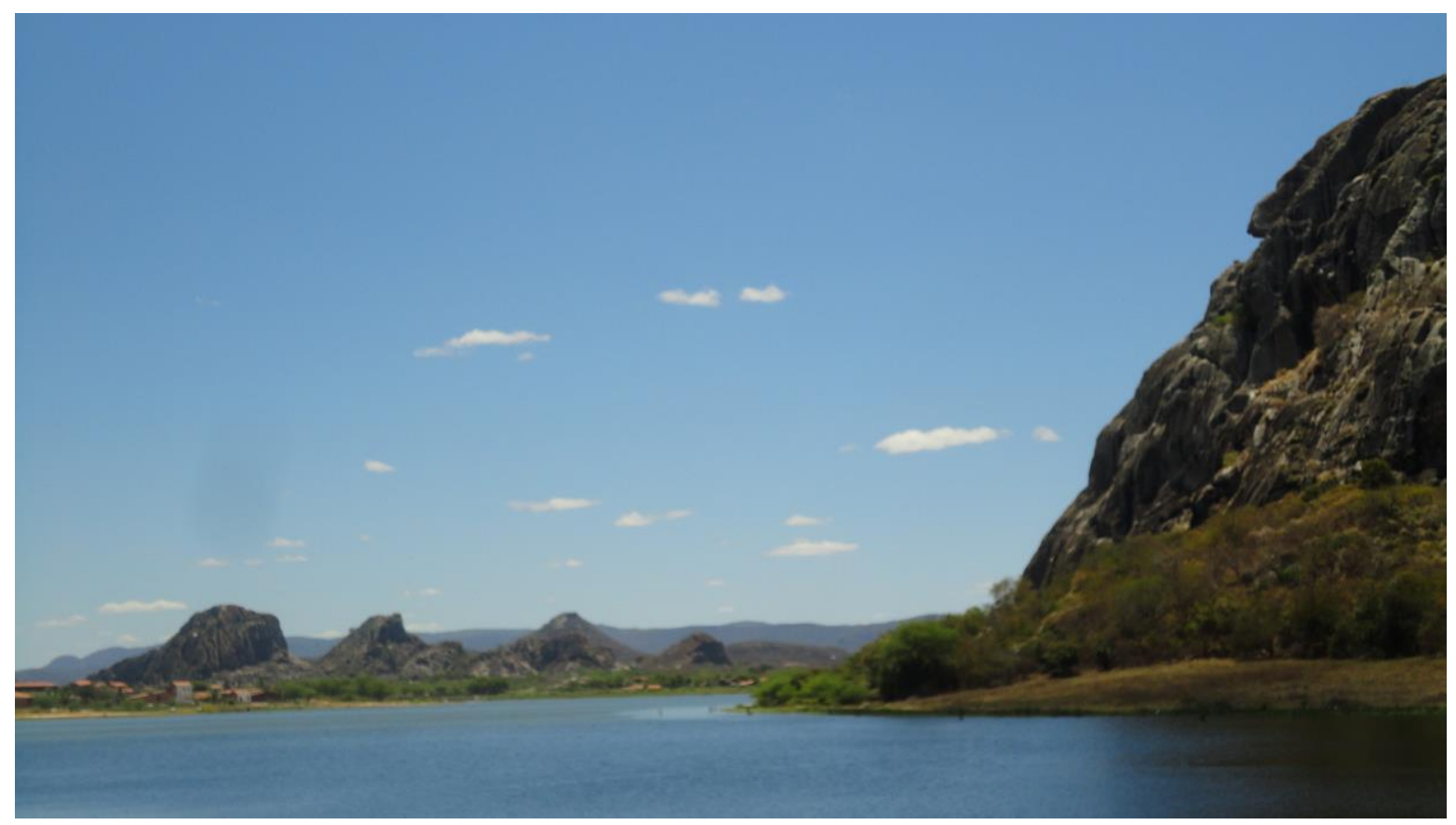

Figura 1: Açude do Cedro com a paisagem dos Monólitos de Quixadá.

Mediante a realidade exposta, referente ao objeto de estudo precisa-se compreender a potencialidade existente na referida UC no que tange o seu acervo patrimonial, onde guarda relíquias históricas e monumentos que remontam à época da colonização portuguesa, pois, assim, o turismo em áreas protegidas abre perspectivas para a valorização e revitalização do patrimônio e da geodiversidade, do revigoramento das tradições, da redescoberta de bens culturais materiais e imateriais, muitas vezes reprimidas pela concepção consumista moderna.

A delimitação desse estudo foi orientada a partir da percepção de que a preservação do patrimônio natural e cultural se apresentam como essenciais para a memória da UC, na medida em que possibilita o reencontro com as raízes das suas comunidades e a reafirmação das suas identidades, bem como, transformando-se em potencial atrativo no planejamento turístico municipal.

Sob essa ótica, o presente trabalho visa reconstruir um cenário, onde a atividade turística passa necessariamente pela questão da cultura local e da geodiversidade do território da UC, reforçando a 
necessidade em compreender as suas memórias, investigar as peculiaridades de seu patrimônio e estimular a participação da comunidade no que diz respeito à conservação do seu legado histórico. E sob essa temática apresenta-se como problema de pesquisa: Como a relação entre identidade, memória e conservação pode contribuir para o desenvolvimento do turismo com enfoque no patrimônio cultural e natural da UC estadual? O objetivo geral do trabalho é analisar como a identidade, a memória e a conservação podem contribuir para o desenvolvimento do geoturismo, utilizando elementos do patrimônio cultural do Monumento Natural Os Monólitos de Quixadá. Para o alcance desse objetivo, delinearam os seguintes objetivos específicos: averiguar se há identidade cultural da população com a sua cidade; compreender a importância histórica do patrimônio cultural da UC para o desenvolvimento local; avaliar a participação dos atores relacionados com o turismo na elaboração de políticas/ações para o geoturismo em UC; apontar os impactos positivos e negativos já existentes e potenciais em decorrência da atividade turística na UC.

Dessa forma, o geoturismo ao mesmo tempo em que oferece ao visitante um aprofundamento sobre as origens do ambiente com base em informações geológicas, constitui igualmente um elemento essencial para incluir pessoas no contexto das discussões e reflexões que tratam do conflito homem $\mathrm{x}$ meio ambiente (PIRANHA; DEL LAMA; LA CORTE, 2009).

Para Bomfim (2006), muitos autores têm percebido que a história humana acaba por predominar sobre os fatores naturais na configuração de regiões. Outros acrescentam, ainda, o sentimento de pertença com a consciência da tradição e de ideais comuns, considerando ainda que o binômio homem-meio ainda não foi incorporado como uma das grandes dimensões da identidade.

Logo, a identidade de um povo é primordial para a reversão da tendência em curso e seu fortalecimento serve como base para a valorização e geoconservação do lugar.

\section{Procedimentos Metodológicos}

A metodologia científica pode ser compreendida, de forma resumida, como a soma de técnicas e processos empregados na realização de uma pesquisa, sendo que as técnicas corresponderiam às atividades sistematizadas e racionais que permitem alcançar os objetivos, delineando o caminho metodológico a ser seguido (MARCONI; LAKATOS, 2003).

Nesse sentido, foram duas técnicas empregadas nessa pesquisa:

1- Documentação indireta: refere-se ao levantamento de dados em fontes primárias e secundárias através de:

- Pesquisa documental: realizada no arquivo do Monumento Natural Os Monólitos de Quixadá, onde foi possível ter acesso a relatórios e pesquisas geoambientais.

- Pesquisa bibliográfica: baseou-se no levantamento, localização, fichamento e, por fim, análise e interpretação de obras pertinentes ao tema, a partir de quatro eixos principais: 
I- Geodiversidade, geopatrimônio, geoconservação e geoturismo, II- Caracterização da área de estudo e IIIInterpretação ambiental

2- Documentação direta: corresponde ao levantamento de dados no próprio local onde os fenômenos ocorrem, nesse caso, o Monumento Natural Os Monólitos de Quixadá, através de pesquisa de campo. Foi realizada em duas etapas, uma no ano de 2015 e outra em 2016, totalizando cerca de 20 dias, com o objetivo de compreender melhor as características naturais e culturais da área de estudo, bem como entrevistar os 50 (cinquenta) atores envolvidos com a temática em questão, dentre esses participaram 35 (trinta e cinco) pessoas da comunidade local inserida na UC; 5 (cinco) membros atuantes do governo local; e 10 representantes da iniciativa privada que tem relação com a UC. Nessas visitas a campo, possibilitou-se também identificar, georreferenciar e fazer o registro fotográfico dos atrativos de base abiótica e cultural.

\section{Discussões e Resultados}

\subsection{Apreciação do legado histórico: a relação da geoconservação do patrimônio com o desenvolvimento local}

A identidade cultural e a memória coletiva, bem como suas diferentes expressões na preservação do patrimônio intangível, são extremamente importantes para a compreensão do vínculo entre o patrimônio cultural, natural e os direitos da coletividade.

A criação do município de Quixadá data do século XVIII, quando os índios Kanindés e Jenipapos, pertencentes ao grupo dos Tapuias teve vencida a sua resistência, no momento em que Manuel Gomes de Oliveira e André Moreira Barros ocuparam as terras por eles habitadas. Em 1728, essas terras foram adquiridas, por compra, por Manoel da Silva Lima, conforme escritura de 18 de dezembro do ano citado. Em 1747, as terras foram vendidas a José de Barros Ferreira, que construiu casas de morada, capela e curral, bases da atual cidade de Quixadá, sendo considerado, o legítimo fundador da cidade. A fazenda prosperou e transformou-se em distrito do município de Quixeramobim, “podendo-se dizer que Quixadá teve seu início de história datado de 1747” (COSTA, 2002, p.12).

Deste modo, a geoconservação baseia-se no ato de proteger e de conservar algo, onde se atribuiu algum valor. O objetivo da geoconservação é a conservação e a gestão do patrimônio geológico e a todos os processos naturais a ele associados, assim como a sua utilização sustentável, incluindo todo o tipo de ocorrências e recursos geológicos (BRILHA, 2005).

Baseado nesses fundamentos e nas respostas colhidas por meio do questionário pode-se dizer que a identidade cultural do povo quixadaense é muito forte, genuinamente nordestina, representada pelos profetas da chuva pelos repentistas, pelo bumba meu boi, pelas festas populares, pelo artesanato, pelas crenças e crendices, o que proporciona o conhecimento dos hábitos culturais e a forma como o sertanejo se relaciona 
com os recursos naturais da Caatinga.

Mesmo se tendo ciência de que o sentimento sobre os monólitos do povo quixadaense é forte, $64,44 \%$ de seus protagonistas, representados pelos participantes dessa pesquisa, afirmam que o meio ambiente está sendo esquecido. As causas são as mais diversas, dentre as quais se destacam a inexistência de políticas públicas, a falta de interesse político e da própria comunidade; a globalização de hábitos e consumos, atitudes e valores introduzidos pelos jovens. Fazem coro a essa afirmação, os entrevistados comerciantes e comerciários, ao colocarem que o fator principal da não preservação do meio ambiente local são a falta de investimentos, educação ambiental e de políticas públicas.

Os entrevistados da iniciativa privada, embora acreditem que há preservação da cultura e da natureza, ressaltam a dificuldade nesse sentido por falta de incentivo do governo municipal. Entretanto, outra parte deste segmento tem opinião divergente. As pessoas afirmam que a cultura em Quixadá é preservada porque o povo vive cultivando sua cultura e sua gente; porque a população tanto preserva os costumes como as crenças, a fé e se orgulha da beleza que são os seus monólitos. Há, também, entre secretários e comerciários, os que consideram que as pessoas têm em si espírito tradicional, por isso preservam bem os costumes, hábitos e crenças, e que esse trabalho conta com o apoio da população e das leis de preservação. Ainda com respeito a esse aspecto, argumenta-se que a preservação cultural se dá também por conta de instituições ali instaladas como as faculdades e o IFCE que procuram incentivar os movimentos culturais. As entrevistas consideraram a atuação efetiva da Fundação Cultural por meio dos eventos por ela realizados.

Em Quixadá, a cultura manifesta-se por meio das festas populares e religiosas, do artesanato e dos esportes, que na cidade são chamarizes para a visitação turística. Pela pesquisa, as festas tradicionais de maior visibilidade são: a quadrilha junina $(21,48 \%)$; o forró $(19,62 \%)$, o carnaval $(18,62 \%)$ e a vaquejada $(18,19 \%)$ da amostra pesquisada. Diante das respostas, as festas preferidas da população local e regional são a quadrilha e o forró, o que não poderia ser diferente, visto que, excetuando-se o carnaval que tem amplitude nacional, as demais fazem parte do folclore nordestino, pertencem à cultura regional e refletem as raízes de seu povo.

Como já visto anteriormente, a paisagem natural de Quixadá, dotada especialmente de originais monólitos, configura-se como de uma beleza ímpar, inclusive, tem servido de cenário para diversas produções cinematográficas. Alguns filmes foram ali rodados, tais como: "O Cangaceiro Trapalhão", "O Quinze”, "O Auto da Camisinha", o "Área Q", ora em exibição nos cinemas e "Gato Preto", ainda não estreado. A cidade possui poucos equipamentos culturais: o Museu Histórico Jacinto de Sousa, o Centro Cultural Rachel de Queiroz, com dois pavimentos, um teatro e um anfiteatro, que oferecem oficinas de audiovisual, música, teatro e artes plásticas. Entretanto, a população sente falta de incentivo por parte de órgãos do governo, em todas as esferas administrativas, e de parte da população.

A partir desse cenário, pode-se inferir que: 


\section{OS DESAFIOS DA GEOGRAFIA FÍSICA NA FRONTEIRA DO CONHECIMENTO \\ Instituto de Geociências - Unicamp \\ Campinas - SP \\ 28 de Junho à 02 de Julho de 2017}

Transformando os recursos da região em arte, extraindo do solo, dos monumentos naturais, da fauna e da flora o seu sustento e, a partir desse manejo, mantendo a subsistência da comunidade, o nativo região de Quixadá torna possível uma exploração consciente e racional dos bens. E, no equilíbrio entre trabalho e meio ambiente, oferece o resultado de uma cultura profundamente enraizada, com produtos que revelam a criatividade e a versatilidade de artesãos populares, intimamente sintonizados com suas mais caras tradições (VON BEHR, 2007, p. 34).

Em Quixadá, em particular, a cultura e a geodiversidade peculiar sobrevivem no imaginário popular e é preservada, em parte, devido à transmissão oral de geração a geração, muito mais do que por iniciativas ou ações derivadas de políticas públicas, como se pode constatar nesta pesquisa. Há certo desinteresse pelas "coisas da terra" por parte das pessoas mais jovens que procuram outras formas de expressão cultural, copiando modas, modismos, atitudes, hábitos e comportamentos de outras regiões, tangidos pela força da mídia. As poucas atividades culturais resumem-se às festas populares como São João, festa da padroeira, encontro dos profetas das chuvas, carnaval e vaquejadas, as quais, de alguma forma, contribuem para o incremento do turismo na região.

Constata-se que, o turismo no Nordeste cresce em ritmo acelerado e em todos os sentidos: na quantidade de turistas que visita à região e, consequentemente, no volume de capital gerado pela atividade. $\mathrm{O}$ espaço turístico é, sobretudo, um espaço geográfico e constitui, portanto, "uma realidade objetiva, um produto social em permanente processo de transformação" (SANTOS, 1996).

Algumas cidades, por sua localização e situação geográfica, são propícias aos investimentos do capital, na forma de oferta de bens e serviços - a indústria do turismo e Quixadá é uma delas. Devido à beleza de suas paisagens, o município apresenta grande potencial para se desenvolver como polo turístico no Sertão Central, especialmente no que se refere ao geoturismo e turismo cultural. As atividades geoturísticas ali desenvolvidas, ainda são ínfimas, talvez pela falta de incentivo estatal ou de visão empresarial, fazendo com que se percam oportunidades de desenvolvimento, por meio da exploração dos recursos naturais. Não existem políticas públicas locais para implementá-las, sendo que os poucos empreendimentos ali instalados vêm de fora e são organizados por empresas que utilizam o espaço geográfico, seu relevo e paisagem para tal fim.

A natureza propiciou uma paisagem belíssima à região de Quixadá: seus monólitos, alguns em pleno centro da cidade ganham, na percepção dos indivíduos pesquisados, formas diversas e são usados para a prática somente de esportes radicais; uma vegetação de caatinga, que mesmo com um clima quente e seco, no inverno, enche os olhos com seu verdor e, no período de estiagem, mostra toda a beleza de uma natureza que espera renascer à primeira gota d'água caída do céu; um povo hospitaleiro e simples; um comércio pujante e em crescimento.

Porém, como frisado pelos pesquisados, faltam políticas públicas para o incremento de atividades geoturísticas mais sistemáticas e contínuas; faltam empreendedores e formação profissional mais focada nesse sentido; falta vontade política e investimentos para alavancar tal atividade que, se bem conduzida, pode 
oportunizar emprego e renda para a população local e regional.

\subsection{A herança dos Monólitos de Quixadá: reflexões, impactos e transformação para o geoturismo}

O geoturismo é uma atividade que se baseia na geodiversidade, embora nem todas as definições relacionem a geodiversidade de modo inequívoco. De acordo com a National Geographic Society o geoturismo é considerado no conceito de turismo sustentável, onde procura minimizar o impacto ambiental e cultural sobre as comunidades que recebem os fluxos turísticos, permitindo a manutenção das características genuínas do local, nomeadamente, o seu ambiente, cultura, estética, patrimônio e o bem- estar das populações (BRILHA, 2005).

Sob um novo olhar, o geoturismo tem se apresentado como um segmento promissor da atividade turística que tem características específicas e essenciais à conservação do patrimônio geológico e ao desenvolvimento econômico local das comunidades envolvidas.

De modo geral, o geoturismo constitui um segmento de turismo emergente, onde o objetivo do turismo se centra na geodiversidade. Para a definição de uma estratégia de geoturismo é fundamental analisar todas as particularidades relacionadas com o patrimônio geológico, não esquecendo as propostas de conservação inerentes a este, pois são precisamente todas estas circunstâncias que irão ditar e suportar o tipo de atividades a desenvolver, no âmbito do geoturismo (RODRIGUES, 2009).

Para tanto, quando se trabalha com herança e simbolismo, deve-se ter uma abordagem em que o ponto de partida é a representação revelada pelos pontos de vista populares. E como forma de compreender o conceito de símbolo, Bourdieu (1976, p.82) afirma que, "é a resultante das condições sociais [...]".

Observa-se que os símbolos mais mencionados pelos entrevistados do grupo da comunidade foram: o Açude Cedro, a Pedra da Galinha Choca, o Santuário N. Senhora Imaculada Rainha do Sertão, o Chalé da Pedra, a Lagoa dos Monólitos, a Pedra do Cruzeiro, a Serra do Estevão e a Gruta de São Francisco. Os resultados da pesquisa mostraram que a população tem esses pontos turísticos como os mais visitados. O Açude Cedro e o Chalé da Pedra são os mais requisitados (26,35\% e 25,75\%, respectivamente), seguidos do Santuário, com 18,36, e da Pedra da Galinha Choca, com 11,38 da preferência dos respondentes do questionário.

A pertinência do diálogo continua para comprovar que a conservação dos bens culturais deve e pode assim contribuir para o desenvolvimento do geoturismo local. Acredita-se que na atividade turística as mudanças, referentes à cultura, à geodiversidade têm estabelecido uma relação simbiótica, de um lado o geoturismo pode ser e oferecer incentivos diversos para:

"manutenção e revitalização de diversas atividades culturais [...] da mesma forma, os efeitos que o turismo pode causar nas tradições locais podem ser desastrosos, e ao invés de reavivar a memória local, pode apagá-la ou descaracterizá-la”. (BELFORT, 2004, p.09). 
Ao perguntar sobre o que eles sabiam sobre a história de Quixadá, verificou-se certa apatia e desconhecimento nas respostas, de modo tal que os três grupos consultados, apenas o grupo do governo sobressaiu-se um pouco melhor sobre o assunto. Diante dessas conversas, pode-se ter a nítida impressão de que aquilo que era explanado pelos representantes do governo, se configurava em um conhecimento mecânico, sem emoção e sem representar uma identidade com a riqueza histórica local.

Desse modo, é imprescindível uma cooperação de todos os atores envolvidos para conhecer, ordenar e/ou classificar todos os bens que compõem o patrimônio cultural de Quixadá em prol de novos segmentos da atividade turística.

Face ao exposto, cabe mencionar Tulik (1990), pois ela admitia, com uma visão abrangente, que o turismo estimulava a existência e a reabilitação de sítios históricos, construções e monumentos, por meio de sua transformação em recurso recreacional.

Assim, estudos internacionais mostram que o geoturismo propicia a revitalização de atividades tradicionais de áreas em declínio, a redescoberta de sítios com propriedades específicas e de cidades históricas, estimulando a transformação de antigas habitações em acomodações turísticas, mantendo a estrutura e as características tradicionais.

Infere-se, que ao questionar esses pontos na pesquisa, compreendeu-se a real importância da história de Quixadá apenas no contexto geral de representatividade para o Estado, já que, no foco local, a amostra pesquisada mostrou-se inativa ao universo cultural existente em Quixadá. Vale ressaltar que a participação comunitária é uma prerrogativa para a implantação do geoturismo, pois é através dela que se fortalecerão os traços de identidade junto com o seu patrimônio natural e cultural.

Sob essa ótica, procurou-se investigar a opinião dos quixadaenses sobre as perspectivas do geoturismo voltado ao patrimônio cultural da cidade. Apesar de seu potencial para esse segmento, o município de Quixadá não vem desenvolvendo atividades voltadas para este segmento, que causaria menos impactos no local, dada as implicações no planejamento diferenciado para os produtos geoturísticos e no comportamento das pessoas interessadas neste tipo de atividade, contrária às práticas de turismo que vêm sendo incentivadas no município.

A conservação e a gestão do patrimônio natural constituem importantes condicionantes no âmbito do ordenamento do território. A inclusão do patrimônio geológico e das respectivas estratégias de conservação nas políticas de ordenamento territorial nacional/regional/local promovem a sua valorização (BRILHA, 2009).

Constatou-se que a relação contraditória entre sociedade e natureza é antiga entre nós. Admite-se que, nos últimos anos, com a inserção de novas relações sociais de produção, esse quadro se agravou sensivelmente. É importante reconhecer que os mais antigos expressavam uma postura de mais respeito em relação ao meio 
ambiente dominante.

\section{Considerações Finais}

Neste contexto, às Unidades de Conservação cabem papéis significativos quando buscam proteger espaços territoriais criados pelo poder público, delimitados com o objetivo de assegurar a conservação de seus recursos ambientais, possuindo características naturais relevantes, sendo submetidos a um regime especial de administração e adequada proteção. Assim, tais espaços ambientais são porções delimitadas do território cearense, especialmente protegidas para garantir a preservação do meio ambiente e defender a geopatrimônio local.

Espera-se que as Unidades de Conservação sejam ampliadas, diversificadas e interconectadas, aliadas ao respeito cultural e saber especializado das comunidades tradicionais, e à promoção da qualidade ambiental e de vida para uma sociedade rumo à sustentabilidade. Paralelamente a isso, o poder público, junto com a coletividade, tem que se articular para implementar uma política de fiscalização e monitoramento, dentro e no entorno dessas áreas, capaz de garantir a integridade dos ecossistemas sob o seu domínio.

Como se vê, ao longo do trabalho exposto, estimular o geoturismo nas Unidades de Conservação, criar mecanismos de preservação de ambientes frágeis e incentivar a sustentabilidade no uso de seus recursos é o desafio assumido pelo Governo do Estado em resposta aos anseios do povo cearense. Nesse contexto, o belo, o singular, o exótico aparecem como incentivo ao sentimento de se contemplar e valorizar o que é do cearense, propiciar aos diferentes olhares o conhecer, o sentir para agir e conservar, contribuindo, desse modo, para a sustentabilidade da gestão dos recursos naturais e para a valorização da geodiversidade do Estado.

\section{REFERÊNCIAS}

BELFORT, C. A relação entre turismo e cultura popular. In.: Itinerários revista científica de turismo. São Luís-MA. v. 01. n. 01, p.7-12, 2004

BENI, M. C. Análise estrutural do turismo. 6 ed. São Paulo: SENAC, 2001.

BOMFIM, L. C. E. O turismo como alternativa de desenvolvimento local no município de Presidente Epitácio: representações sociais e culturais de identidade local. Dissertação (Mestrado em Desenvolvimento Local). Universidade Católica Dom Bosco (UCDB), Campo Grande, 2006.

BOURDIEU, P. A economia das trocas simbólicas. São Paulo: Perspectiva, 1976.

BRILHA, J. Patrimônio Geológico e Geoconservação: A Conservação da Natureza na sua Vertente Geológica. Viseu: Palimage Editores, 2005. 190p.

A Importância dos Geoparques no Ensino e Divulgação das Geociências. Revista do Instituto de Geociências - USP. São Paulo. Volume 5. p. 27 - 33, 2009.

CANCLINI, N. G. O patrimônio cultural e a construção imaginária do nacional. Revista do Patrimônio Histórico e Artístico Nacional, Brasília, n. 23, 1994, p. 94-115.

COSTA, J. E. C.. Retalhos da história de Quixadá. Fortaleza: ABC Editora, 2002. 602p. 
GRAY, M. Geodiversity: valuing and conserving abiotic nature. Wiley, Chichester, UK, 2004.

LAKATOS, E. M.; MARCONI, M. de A. Fundamentos de metodologia científica. 5. ed. São Paulo: Atlas, 2003.

MUGGLER, C. C. Desafios para a educação em solos e a questão ambiental. In: CONGRESSO BRASILEIRO DE CIÊNCIA DO SOLO, 31. 2007. Disponível em: 〈http://www.ufgrs.br>. Acesso em: 29 de janeiro 2016.

PIRANHA, J. M; DEL LAMA, E. A; LA CORTE, D. Geotourism and local development: potentialities and risks. In: CARVALHO, C. N. de; RODRIGUES, J. New challenges with geotourism. Portugal: 2009, p. 87- 88. Disponível em: www.dct.uminho.pt/docentes/pdfs/jb_naturtejo4.pdf. Acesso em: 15 de dezembro de 2015.

RODRIGUES, C. J. Geoturismo - Uma Abordagem Emergente. 37 - 61. In NETO DE CARVALHO, C.: RODRIGUES, J. C. (Edts.). Geoturismo \& Desenvolvimento Local. Edição Câmara Municipal de Idanha-aNova/Geopark Naturtejo da Meseta Meridional/UNESCO European and Global Geopark, Idanha-a-Nova, 2009.

SANTOS, M. A natureza do espaço: técnica e tempo, razão e emoção. 2.ed. São Paulo: Hucitec, 1996. 293p.

SERRANO CAÑADAS, S. e RUYZ FLAÑO, P. Geodiversidad: Concepto, Evaluación y Aplicación Territorial. El caso de tiermes Caracena (Soria). Boletín de la A.G.E. No45, 2007.

TULIK, O. Turismo e repercussões no espaço geográfico. Turismo em Análise, ECA-USP. p.63-77, 1990.

VON BEHR, M. Quixadá: Terra dos Monólitos. São José dos Campos: Somos Editora, 2007. 303p. (Série Ecossistemas Brasileiros). 